\title{
APPOINTMENT DELAY AND THE POLICY ENVIRONMENT OF THE NATIONAL TRANSPORTATION SAFETY BOARD
}

\author{
DAVID C. NIXON \\ ROISIN M. BENTLEY \\ Georgia State University
}

\begin{abstract}
Appointments to regulatory agencies are rarely the subject of empirical analysis, and when they are scrutinized, the focus is institutional factors. Instead, the authors examine the policy environment to determine if external factors influence the appointment process. To illustrate this, accident rates are analyzed to determine their effect on appointment duration at the $\mathrm{Na}$ tional Transportation Safety Board. The most important explanatory variable for delay is a statutorily required cross-party nomination - an institutional factor. However, the policy environment is also important: A 1 standard deviation increase in the accident rate leads to a $30 \%$ increase in vacancy duration for the agency.
\end{abstract}

Keywords: appointment; selection; independent regulatory commission; vacancy

In 1992, the National Transportation Safety Board (NTSB) reported some of the worst airline disaster data in recent memory. The number of flight hours had declined, but the number of accidents held steady or grew. As a result, the accident rate had actually grown $6.5 \%$ from 1991 . The fatality rate grew $15 \%$ between 1991 and 1992. Airline accident rates have fallen in 27 of the past 35 years, so growth in those figures was salient to the public, airlines, and politicians. Carl Vogt was thrown into this policy context as a nominee to the NTSB to replace a board member whose term expired December 31, 1991. Vogt was nominated April 7, 1992, and

AUTHORS' NOTE: This research was supported by Grant SES 00-95962 from the National Science Foundation. The data for this project, along with the appointment and biographical data for 14 other independent agencies, are available at http://www.gsu.edu/ wwwirc.

ADMINISTRATION \& SOCIETY, Vol. 37 No. 6, January 2006 679-694 DOI: $10.1177 / 0095399705282881$

(c) 2006 Sage Publications 
eventually confirmed June 17, 1992. The vacancy for his position thus lasted 197 days. Although his confirmation hearing before the Senate was brief, there is clear indication in the written and oral questions and comments posed by senators that the accident rate increase was on their minds and that they were taking special care to find an appointee with strong safety credentials. ${ }^{1}$

The transportation safety policy context was very different in 1969 . The accident rate had declined more than $8 \%$ from the previous year, which is more typical of the long-run trend. Isabel Burgess was nominated September 17, 1969, and confirmed October 3, 1969. She was replacing a board member who resigned June 15, 1969. Thus, the vacancy she filled persisted only 92 days. NTSB observers will note that with the Burgess appointment, President Nixon established a Republican majority on the board for the first time. Every day of appointment delay meant that decisions were being made by a board deadlocked at 2-2. Similarly, appointment delay was important while President Bush sought confirmation for Carl Vogt in 1992. While the seat remained vacant early that year, the agency issued several reports critical of the Federal Aviation Administration (FAA; see NTSB investigations DCA92MA025, LAX92MA184, MIA92FA115, MIA92IA077A, and MIA92IA077B and NTSB Reports AAR-93/020 and AAR-93/01). Had the seat been filled more quickly, the reports may have been different in tone and conclusion.

We address the following puzzle: Why was the vacancy filled by Vogt more than twice as long as the vacancy filled by Burgess? Was the very different airline accident environment at the root of this difference, or were other equally plausible factors at work? For example, it is well known that the average length of vacancies has been growing in the postWorld War II political environment (Deering, 1987) and appears to have been accelerating in the 1990s, at least for federal judicial appointments (Nixon \& Goss, 2001). Perhaps the trend explains the differences between the Vogt and Burgess appointments. In addition, perhaps the partisan context differed between these settings. Scholars of appointment have offered a host of alternative explanations for appointment delay. But policy outcomes in the area of responsibility for the institution experiencing a vacancy has never been carefully examined as one of the explanations. Our goal is to do just that.

Presidential appointments to federal regulatory agencies have received relatively little attention. Yet vacancies are particularly important for agencies because they affect the voting balance on the panel. Thus far, appointment conflict and negotiation has been viewed as a function of 
internal factors-namely, the relative policy preferences of the important advice and consent players. We address this problem and supplement the literature by examining some external factors-namely, variation in the regulatory and public opinion arenas that affect elected officials and may shape the oversight environment for an agency. Lowi (1969) and most capture theorists suggest that external factors almost never play a role in political oversight or policy making. Yet most researchers since then have perceived a more open policy-making process and a more significant and constant influence of the policy environment on regulatory politics (Heclo, 1978). Beginning with Posner (1974), scholars have recognized that policy failures and their attendant media attention cause the public to demand remedies from Congress (see Baumgartner \& Jones, 1993; Jacobs, 1993). In particular, Quirk (1980) suggests that external factors related to salient accidents and crises are pivotal for agency oversight. This is an important alternative hypothesis that has not been empirically scrutinized with respect to appointment politics.

To begin to address the role of policy outcomes on appointments, we examined appointment success for one particular agency, the NTSB. This allows for an empirical examination of the manner and degree to which appointment conflict is driven by implicit public disapproval of agency performance. Political appointments are "the most important instrument of political control" (Wood \& Waterman, 1991, p. 801) and ensure effective policy monitoring. Data for the project derive, in part, from the Independent Regulatory Commissioner Data Base, a project funded by the National Science Foundation.

\section{NTSB AND APPOINTMENT VACANCIES}

President Johnson created the NTSB in 1967 for the express purpose of investigating accidents and providing safety recommendations and oversight to the FAA. The Department of Transportation Act Amendments (80 Stat. 931) were signed into law in 1966, and the NTSB began operating on April 1, 1967. The agency drew many of its original staff members and some board members from the Civil Aeronautics Board (CAB) and consists of five members serving fixed, staggered, 5-year terms. Like virtually every independent agency, there can be no more than a bare majority ( 3 of $5)$ members from one political party serving on the NTSB. As noted by scholars, most commissioners fail to serve out their full terms of office (Brauer, 1987; Moe, 1982). As a result, the one vacancy guaranteed to 
arise each year is a conservative indication of the president's opportunity to appoint to an independent board. At the NTSB, 24\% of confirmed appointees have resigned before their term expired, and 1.3 vacancies have arisen each year since 1967, on average.

Nominees to all but the Supreme Court are regularly confirmed more than $96 \%$ of the time (Ragsdale, 1998). But the length of time from the opening of a vacancy to the confirmation of a replacement has become an increasingly important component of political conflict and an increasingly important focus of political control. Presidents wish to appoint commissioners who reflect their own ideology. But for the few nominations that do fail, extreme ideology has been cited as a primary reason (Cameron, Cover, \& Segal, 1990; Krutz, Fleisher, \& Bond, 1998). This occurs even though the White House generally will not name a nominee unless he or she has passed the scrutiny of relevant industries or interests (Kohlmeier, 1969). The confirmation process remains primarily political, with nominations being held up and used as political bargaining chips (Mackenzie, 1981).

This research builds on the work of Nixon (2001), who examined appointment delay at the Federal Communications Commission (FCC). The most significant findings were that a vacancy will last longer when it is a president's second term or a cross-party nomination is required by statute and that candidates being renominated will be confirmed more

quickly. ${ }^{2}$ We expect that those same institutional factors will govern NTSB appointment delay.

In addition to the traditional institutional factors, we hypothesize that NTSB vacancy duration will increase in the wake of high-profile airline disasters. The board is associated with both accident investigations and safety recommendations, and the president and Senate will bring closer scrutiny to bear when opportunities arise and to the degree that the airline safety context prompts them to do so. McCubbins and Schwartz (1984) would call this informal oversight because the oversight is incidental to the official function-confirmation.

\section{DATA AND STATISTICAL METHOD}

For any investigation of appointment delay, the question arises of how to measure appointment duration. Binder and Maltzman (2002) use the nominee as their unit of analysis and measure only confirmation delay: the time elapsed between nomination and confirmation. That is, they study 
only that specific stage of the appointment process after a nominee has been named by the president.

For our purposes, focusing on the period between nomination and confirmation is inappropriate. That design assumes that the formal confirmation process in the Senate is the only forum for Senate influence. It seems equally likely that the period from the beginning of a vacancy until a replacement has been nominated will be a period of important appointment negotiation between the president and the Senate. Indeed, the majority of time taken to fill a vacancy occurs prior to nomination by the president. At the NTSB, delay in making a nomination (average $=189$ days) significantly outweighs delay in confirming the president's nominees (average $=$ 100 days).

Furthermore, considering time until nomination and time until confirmation as separate subintervals ignores the inherent interdependence of the presidential and senatorial roles. In formal theories of appointment, mutual anticipation of presidential and senatorial preferences and the search for an acceptable nominee throughout the duration of the vacancy are the central aspects of the process (Hammond \& Hill, 1993; Nokken \& Sala, 2000). There is no reason to expect appointment delay to be perfectly reflected in only one of its subintervals. For example, the correlation between appointment delay and confirmation delay (by definition, a subset of appointment delay) is a paltry .08 at the NTSB. Joseph Nall was confirmed in only 25 days in 1986, but his confirmation capped a protracted appointment struggle that began in 1984. Thus, his confirmation delay constituted only $2 \%$ of the appointment delay for that position. By contrast, George Black was renominated in 1996 and confirmed about a year later-the confirmation delay was $100 \%$ of the appointment delay for his position.

Finally, analysis of confirmation delay as a separate interval risks biased estimates of the effect of independent variables. Failed nominations must be treated as censored observations, but censoring in duration models assumes that the subject eventually experiences the event. Failed nominations are withdrawn or expire sine die and are therefore permanently removed from the risk set. Inappropriate treatment of such subjects as censored results in biased coefficients and inefficient standard errors (Hettinger \& Zorn, 2005; Maller \& Zhou, 1996).

Instead, we use the entire vacancy duration as the unit of analysis. This is the most comprehensive measure, takes into account the full extent of the bargaining and negotiation period, both before and after a formal nomination, and avoids inappropriate censoring. The length of time that a 
vacancy remains open highlights the nuances of negotiation, where longer vacancy duration indicates lack of consensus between the executive and legislature on the direction of the agency. ${ }^{3}$

An exponential regression model of vacancy survival time is employed for this analysis. ${ }^{4} \mathrm{~A}$ seat becomes vacant either through an early resignation or term expiration. ${ }^{5}$ A vacancy duration is defined as the number of days taken to confirm a replacement, and this time period reflects the full extent of the difficulty the two branches experience in coming to an appointment agreement. ${ }^{6}$ The data set was constructed by collecting one observation for each NTSB vacancy that occurred from December 31, 1967, until December 31, 2000. ${ }^{7}$ For each observation, the date the seat became vacant was recorded and the number of days from this vacancy until the president signed the commission to fill the seat is the dependent variable. ${ }^{8}$ A number of independent variables are constructed based on several important facets of the appointment context at the time.

\section{MODEL}

Deering (1987) details numerous reasons why appointment delay has been increasing since the 1950s. Increased media scrutiny of candidates and more input from interest groups have led to more detailed investigations by both the White House and oversight committees. Senators have taken to using the confirmation forum to promote policy ideas. More detailed analyses of policy preferences of candidates are being sought, rather than restricting attention to policy-neutral qualifications. Previous analyses have included a linear trend to account for this phenomenon (Nixon, 2001), but we do not do so in this project because of the very limited degrees of freedom and the lack of a statistically compelling need to do so. As Figure 1 illustrates, there is no trend in vacancy duration during the relatively recent history of this young agency. In addition, a statistical test for inclusion of a linear trend is nonsignificant.

The desire to obtain partisan advantage is an integral part of the political process and structures the negotiations and bargaining over candidates. According to Barrow, Gryski, and Zuk (1996), as a presidential term nears its end, the president is less likely to nominate candidates and have them confirmed. This may be because the most attractive candidates have already been nominated (Havrilesky \& Gildea, 1992) or because opposition senators anticipate a change in White House control (Binder \& Maltzman, 2002). However, past analysis of appointment delay for the 


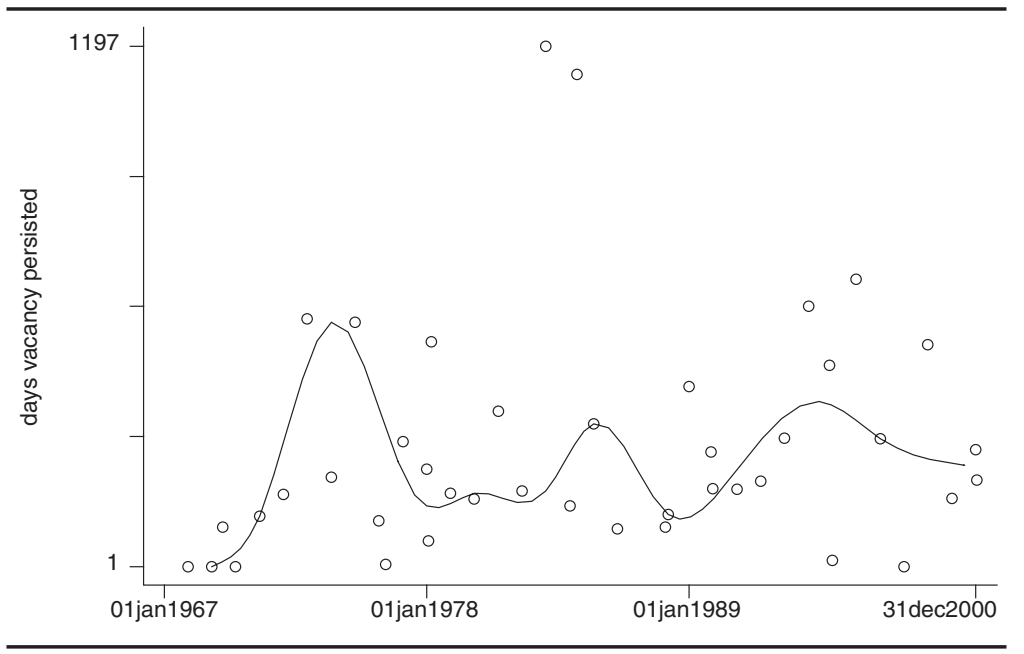

Figure 1: National Transportation Safety Board Appointment Delay

FCC does not indicate a relationship between appointment delay and time to next election (Nixon, 2001).

Instead, anticipation of a change in White House control may structure appointment delay in a less direct manner. Federal judicial appointments are less likely to be confirmed during a president's second term (Hagle, 1993; Nixon \& Goss, 2001; Spriggs \& Wahlbeck, 1995), and FCC vacancies persisted longer during second presidential terms (Nixon, 2001). A dummy variable for whether a vacancy arose during a president's second term has been included to determine if this phenomenon is present at the NTSB.

Anecdotal evidence appears to suggest that nominations take longer to confirm during periods of divided government. However, the evidence supporting this contention is mixed. Some scholars have uncovered evidence that divided government is a significant component of executive branch and appeals courts confirmation delay (Binder \& Maltzman, 2002; McCarty \& Razaghian, 1999). Others have rejected divided government as a significant component of delay for nomination referrals from the Judiciary Committee (Allison, 1996; Hartley \& Holmes, 1997) or for appointment delay for the FCC (Nixon, 2001). In addition, the president has been shown to be able to win confirmation for his executive appointments equally well during divided government (Krutz et al., 1998). Nevertheless, to investigate the generalizability of the FCC findings, we 
included a dummy variable for unified government and hypothesize that vacancies will be filled more quickly in those conditions. ${ }^{9}$

There have been occasions when a seat changes partisan hands, and this has occurred on 11 occasions. According to Ruckman (1993), "critical nominations" at the Supreme Court that change the partisan direction of the Court are subject to extreme opposition by senators. Binder and Maltzman (2002) find evidence for this phenomenon for appeals courts appointment. We hypothesize that when partisan control of a seat changes hands, a vacancy will persist longer.

The 3-2 statutory requirement of partisan balance typical for most independent agencies occasionally presents a more difficult choice for a president and his copartisans in the Senate as they have to locate a candidate whose philosophy is not too removed from their own yet remains acceptable to the senators from the nominee's party. Nixon found this scenario as a significant component of FCC appointment delay. It may be, for example, that the president has little incentive to make a cross-party nomination as long as the agency continues to have a quorum. Conversely, it may be that senators have little incentive to confirm a cross-party nominee because it wastes one of their seats on the board. To examine and control for this element, a dummy variable that indicates whether the vacancy was required to be filled by someone from a party other than the president's party has been included.

The final institutional facet of appointment to consider is that members of regulatory agencies serve fixed terms of office that expire but that reappointment is common. FCC vacancies filled in this manner were significantly shorter in duration than others (Nixon, 2001). At the NTSB, 18 of 42 appointments have been renominations. Because the original nomination is expected to have dealt with all issues of qualification, a reappointment is hypothesized to have a much shorter vacancy duration. To control for this, a dummy variable is included.

Finally, for this analysis, the primary independent variable being tested to explain vacancy duration is airline disasters. As stated earlier, we hypothesize that an increase in commercial airline accidents is linked to longer vacancy duration. Air travel commands greater public attention than do other modes of travel and is the only safety component for which NTSB explicitly compiles summary risk statistics. Rose (1990) argues that accident rates are the most salient and visible measure of the transportation policy environment. Accidents, rather than fatalities or accidents with fatalities, is the factor most clearly linked to airline profitability and compliance with costly programs (Rose, 1990). The percentage annual 




Figure 2: National Transportation Safety Board Policy Environment

change in the general aviation accident rate at the time the vacancy began serves as a predictor of appointment delay. ${ }^{10}$ Figure 2 illustrates the percentage change in the accident rate per 100,000 hours flown for the period relevant for this study. A horizontal line has been superimposed at zerothe point of no change in the accident rate from the previous year. It bears mentioning that the average of this time series is not zero but -4.7 - that is, the accident rate has fallen fairly consistently during the 1965 to 2000 period. ${ }^{11}$ The accident rate grew in only 8 of the 32 years we examined. Data are drawn from the Annual Review of Aircraft Accident Data.

Figure 1 graphically depicts NTSB appointment delay. A comparison of the two figures reveals that variation in accident rates appears to be correlated with vacancy duration. The most obvious evidence is that positive spikes in accident rates in the early 1980s and early 1990s were accompanied by substantial increases in appointment delay.

To summarize, the NTSB seat vacancy duration was modeled as a function of second presidential term at time vacancy occurred $(0=$ no, $1=$ yes), unified government at time vacancy occurred $(0=$ no, $1=$ yes $)$, critical vacancy $(1=$ party control of NTSB seat changed, $0=$ party control of NTSB seat did not change), commissioner renominated $(0=$ no, $1=$ yes $)$, cross-party nomination required by statute $(0=$ not required, $1=$ required), and percentage change in general aviation accidents per 100,000 hours flown in year preceding vacancy commencement. 
TABLE 1

Exponential Regression Model of National Transportation Safety Board Vacancy Duration

\begin{tabular}{lcccc}
\hline Independent Variable & Coefficient & $\mathrm{SE}$ & $\mathrm{p}^{\mathrm{a}}$ & Hazard Ratio \\
\hline Constant & -5.76 & .398 & $.000^{*}$ & \\
Second presidential term & 0.309 & .416 & .229 & 1.36 \\
Unified government & 0.001 & .369 & .499 & 1.00 \\
Renomination & 0.453 & .410 & .135 & 1.57 \\
Cross-party nomination & -0.696 & .340 & $.020^{*}$ & 0.499 \\
Critical nomination & 0.627 & .464 & .089 & 1.87 \\
Accident rate & -0.050 & .398 & $.039^{*}$ & 0.952 \\
Log likelihood & -70.2 & & & \\
$\chi^{2}$ & 10.3 & & & \\
\hline
\end{tabular}

NOTE: $N=42$.

a. $p$ values are one-tailed.

$* p<.05$.

\section{RESULTS}

Table 1 presents the estimates for an exponential regression of vacancy duration for NTSB appointments in proportional hazard form. Coefficients indicate the effect of an independent variable on the hazard rate, which is inversely related to appointment delay. The last column presents coefficients transformed into hazard ratios to ease interpretation. The model significance is poor (the chi-square of 10.28 is not significant with six degrees of freedom), but the low level of overall significance can be attributed to the small number of observations (42) and the large number of nonsignificant variables (4). Diagnostic tests confirm that a more general statistical model is unnecessary for these data. The coefficient for trend in the baseline hazard rate in a Weibull model is not significantly different from $1(t=-.03)$, indicating that there is no trend in the baseline hazard rate. ${ }^{12}$ The coefficient for theta in an exponential regression with frailty is not significantly different from $0(t=0.1)$, indicating that there is no significant heterogeneity in the model errors. ${ }^{13}$

The regression indicates that the variables for cross-party nomination and accident rates are both significant when utilizing a one-tailed significance test. The hazard ratios allow us to interpret the coefficients in a more sensible manner. In addition to being the only two significant variables, cross-party nominations and number of accidents are the only two with lower hazard rates. The hazard rate of filling a vacancy when a cross-party 
nominee is required by statute is $44 \%$ as large as when a same-party nominee is permissible. In other words, on any given day of a vacancy, a crossparty nominee is $56 \%$ less likely to be confirmed than is a same-party nominee, all else equal. A one-unit increase in accident rates leads to a 5\% decrease in the predicted hazard rate or a $5 \%$ decrease in the daily probability of filling the vacancy. Although this figure seems relatively small, it does indicate that a series of disasters can slow down the vacancy process significantly (as is graphically illustrated in Figures 1 and 2). A standard deviation in the annual percentage change in the accident rate during the 33 years examined for this study is 7.24. For a 1 standard deviation increase in the accident rate, the exponential model predicts the hazard rate to decline from $100 \%$ to $69.6 \% .^{14}$ The much smaller hazard rate results in much longer predicted vacancies. The magnitude of the effect for airline accidents is substantial and commensurate with its statistical significance. ${ }^{15}$

Higher hazard rates are associated with all other variables, but none is statistically distinguishable from 0 in this small sample. In some cases, the estimated effect is in the expected direction and appears relatively sizable. For example, the unified government estimate indicates that a nominee is $73 \%$ more likely to be confirmed if the president and Senate majority leader are from the same party. In addition, a board member who is renominated is 55\% more likely to be confirmed, on any given day, than a person who has never served on the NTSB. On the other hand, two findings run contrary to expectations. An appointment during a president's second term has a hazard ratio that indicates his or her probability of being confirmed is increased by $43 \%$ relative to a vacancy arising during a president's first term. In addition, a critical appointment has a $47 \%$ higher likelihood of being confirmed than an appointment that is not critical.

Doubtless the very limited number of appointments is responsible for some perplexing results and the lack of significance in specific instances, so a more detailed discussion of cases helps illustrate and enrich the findings. For example, in 1978 during unified government, President Carter nominated fellow Democrat Elwood Driver to the NTSB. The previous year's accident rate had declined by $5.6 \%$. The actual vacancy duration for that seat was 60 days, and our exponential model predicted that it would persist 67 days. Carter made another nomination in 1978 (Republican Patricia Goldman), and we hypothesized that such a cross-party vacancy would take longer to fill. The exponential model predicted the vacancy would last for 152 days, and it actually persisted for 169. Driver and Goldman are similar in most important respects—same policy 
environment, same president, same Senate. But they differed in one important respect: Goldman, a Republican, was chosen by Carter, a Democrat, to fulfill a statutory obligation to balance the NTSB. As a result, Goldman's appointment took more than twice as long.

To understand the effect of unified government, Elwood Driver's appointment remains an instructive case when compared to the vacancy filled by Webster Todd. The accident rate had declined by $6.1 \%$ from the previous year when President Ford nominated fellow Republican Todd in 1975. That situation is not much different than the 1978 policy context, and both Driver and Todd shared the party of their nominating president. The primary difference was that the Todd vacancy arose during a period of divided government, whereas the Driver vacancy arose under unified government. The actual Todd vacancy was 106 days in duration, and the exponential model predicted it to last 168 days, well more than twice as long as the Driver appointment.

Finally, our purpose in this article was to estimate the effect that accident rates have on the appointment process at the NTSB. For this question, it makes sense to revisit the appointment puzzle posed at the outset of the article-the comparison of the appointment vacancies for Isabel Burgess in 1969 and Carl Vogt in 1992. Both were nominated during periods of divided government, but neither was a cross-party nominee or a critical appointment. However, the accident rate had fallen by $8.74 \%$ in 1969 and had grown $3.20 \%$ in 1992. For Burgess, the predicted duration was 100 days, and the actual vacancy lasted 92 days. For Vogt, the predicted duration was 269 days, and the actual vacancy lasted 197 days. All of the important contributors to appointment delay at NTSB have been controlled in this pairing. Therefore, it does appear that the increased accident rate in 1992 extended the Vogt vacancy. The special emphasis given to safety questions during the appointment process was indicative of the political problem. The scenario is emblematic of a consistent phenomenon at the NTSB: The policy environment has a significant and substantial effect on the ability of the president and senators to quickly agree on a candidate to fill a vacancy.

\section{DISCUSSION AND CONCLUSION}

The empirical results, together with three instructive comparisons, indicate that our model aids in predicting vacancy duration at the NTSB and helps offer explanations for variations in appointment delay at the 
agency. Institutional factors such as divided government and cross-party nomination requirements do slow down the process, as expected. But external factors normally ignored by appointment scholars and dismissed by Lowi (1969) as rarely important do indeed bear on the appointments process after all. More recent scholarship suggests that accidents and policy failures, especially those generating media attention, create conditions for heightened oversight by the political branches (Baumgartner \& Jones, 1993; Posner, 1974; Quirk, 1980). As the airline accident rate increases, greater scrutiny is brought to bear on potential NTSB appointees, with the result that seats on the board remain vacant longer.

Institutional factors clearly play a role in the appointment process. In that respect, this set of results reinforces previous conclusions about appointment delay for independent agencies. But for agencies with a defined responsibility in a policy arena with salient policy outcomes, such as the NTSB, the policy environment is also a significant predictor of vacancy duration. Further work may help shed light on the generalizability of this result. Do accidents affect appointments for similar agencies such as the FAA or the now defunct CAB? Is TV language and violence related to FCC appointment delay? Is stock market performance related to SEC appointment scrutiny, or was public dissatisfaction with railroad regulation ever related to appointment politics for the ICC?

In addition, future research might seek to probe the precise bases for the importance of accident rates in NTSB appointment delay. Are difficulties of appointment negotiation rooted in consideration of mass constituencies, clientele pressures, or none of the above? We have shown that changes in airline accident rates are related to appointment negotiation, but it remains to be explored whether this is a dynamic driven by "inside the beltway" or "outside the beltway" pressures.

\section{NOTES}

1. See the nomination of Carl W. Vogt to the Chairman and Member of the National Transportation Safety Board, hearing before the Committee on Commerce, Science, and Transportation, United States Senate, May 7, 1992.

2. Nixon (2001) also examined the effect of candidate race and gender and found that race, a salient component of Federal Communications Commission policies, is a significant factor in appointment delay and that gender is not a significant factor. For this study of National Transportation Safety Board (NTSB) appointments, we focus on external factors unrelated to specific candidate qualities. Neither gender nor race is a salient component of NTSB policies. 
3. Our theoretical and methodological arguments against parsing nomination from confirmation delay notwithstanding, we conducted separate analyses of the two indicators and found that both confirmation delay and nomination delay at NTSB are significantly increased by higher airline accident rates ( $p=.05$ and $p=.002$, respectively). Thus, our primary finding about the effect of the policy environment on NTSB appointments is not driven by our methodological choice to focus on the entire vacancy.

4. A Cox regression is often preferred in duration modeling but is inappropriate in the NTSB context because the number of tied observations violates Yamaguchi's (1991) 5\% rule.

5. For unexpired terms, a vacancy begins the day the previous board member ceases to serve, not when a resignation or retirement is announced.

6. A board member whose term has expired can continue to serve in a holdover position until he or she is reconfirmed or replaced. Such seats are deemed to be vacant on the day the term expired because an agreement between the president and the Senate has not been reached.

7. The first five board members have been excluded because they were all confirmed on the same day, and the dynamics of these appointments are logically distinct from later nominations.

8. Recess appointments have been ignored because although they allow for the NTSB to continue to function, they also indicate that consensus has not been reached between the president and the Senate. The vacancy was not considered filled until the Senate confirmed the nominee.

9. We defined unified government as periods when the Senate majority and the White House were held by the same party. The House has no constitutional role in appointment, though there are anecdotal accounts of intrusion in the appointment process by House oversight chairs (Mackenzie, 1981). If unified government is measured to incorporate House majority control, the coefficient is still statistically non-significant $(p=.185)$, and no other coefficients change in direction or significance. To provide an aggressive search for an effect of divided government on NTSB appointments, we also included an interaction between divided government and partisan polarization in the Senate. One might hypothesize that divided government has a more noticeable negative effect on the odds of a vacancy's being filled when Democrats and Republicans are more unified against one another in the Senate. In that case, the coefficient for the interaction term should be negative and significant. When polarization is measured as either the percentage of all Senate roll calls classified by Congressional Quarterly (CQ) as "party votes" or the average CQ "party unity score" for all senators in the year prior to a vacancy, the results do not support the hypothesis with respect to direction or significance.

10. Alternative measures of air accidents are possible but are not linked to appointment delay. For example, we subsequently substituted the number of U.S. air accidents with at least one fatality in place of our annual percentage change in the U.S. air accident rate, and the effect cannot be distinguished from $0(p=.43)$. We also substituted the number of U.S. air traffic fatalities, which also has no statistical effect on NTSB appointment $(p=.47)$. Even annual percentage changes in those figures are unrelated to NTSB appointment delay ( $p=.40$ and $p=.39$, respectively). We take all of this as confirmation of Rose's (1990) view that changes in the accident rate are the politically important phenomena.

11. The steady decline in accident rates is another reason to use annual change as a predictor. Year-to-year variation in the accident rate is swamped by the powerful, long-run decline between 1967 and 2000. 
12. A trend in the baseline hazard would induce biased coefficients in an exponential regression.

13. Heteroscedasticity in the residuals would induce bias in the estimated standard errors of an exponential regression.

14. The calculation is $\exp [7.24 \times-.050]=.696$.

15. One might conjecture that vacancies arising under Republican administrations will be delayed more than those arising under Democratic administrations in response to relative increases in the accident rate. Republican presidents may seek to slow the appointment process in such circumstances until the ardor for more safety-oriented appointees has passed.

However, inclusion of an interaction term between change in accident rate and vacancies arising under Democratic administrations turns up as not significant.

\section{REFERENCES}

Allison, G. W. (1996). Delay in senate confirmation of federal judicial nominees. Judicature, 80(1), 8-15.

Barrow, D., Gryski, G., \& Zuk, G. (1996). The Federal judiciary and institutional change. Ann Arbor: University of Michigan Press.

Baumgartner, F. R., \& Jones, B. D. (1993). Agendas and instability in American politics. Chicago: University of Chicago Press.

Binder, S. A., \& Maltzman, F. (2002). Senatorial delay in confirming federal judges, 19471998. American Journal of Political Science, 46, 190-199.

Brauer, C. (1987). Tenure, turnover, and post-government employment trends of presidential appointees. In G. C. Mackenzie (Ed.), The in-and-outers (pp. 174-194). Baltimore: Johns Hopkins University Press.

Cameron, C. M., Cover, A. D., \& Segal, J. A. (1990). Senate voting on supreme court nominees: A neoinstitutional model. American Political Science Review, 84, 525-534.

Deering, C. J. (1987). Damned if you do and damned if you don't: The Senate's role in the appointments process. In G. C. Mackenzie (Ed.), The in-and-outers (pp. 100-119). Baltimore: Johns Hopkins University Press.

Hagle, T. M. (1993). Strategic retirements: A political model of turnover on the United States Supreme Court. Political Behavior, 15(1), 25-48.

Hammond, T. H., \& Hill, J. S. (1993). Deference or preference? Explaining Senate confirmation of presidential nominees to administrative agencies. Journal of Theoretical Politics, 5, 23-59.

Hartley, R. E., \& Holmes, L. M. (1997). Increasing Senate scrutiny of lower federal court nominees. Judicature, 80, 274-278.

Havrilesky, T., \& Gildea, J. (1992). Reliable and unreliable partisan appointees to the board of governors. Public Choice, 73, 319-417.

Heclo, H. (1978). Issue networks in the executive establishment. In A. King (Ed.), The new American political system (pp. 87-124). Washington, DC: American Enterprise Institute.

Hettinger, V., \& Zorn, C. (2005). Explaining the incidence and timing of congressional responses to the U.S. Supreme Court. Legislative Studies Quarterly, 30, 5-28.

Jacobs, L. R. (1993). The health of nations: Public opinion and the making of American and British health policy. Ithaca, NY: Cornell University Press. 
Kohlmeier, L. M., Jr. (1969). Regulators: Watchdog agencies and the public interest. New York: Harper and Row.

Krutz, G. S., Fleisher, R., \& Bond, J. R. (1998). From Abe Fortas to Zoe Baird: Why some presidential nominations fail in the Senate. American Political Science Review, 92, 871881

Lowi, T. J. (1969). The end of liberalism: Ideology, policy, and the crisis of public authority. New York: Norton.

Mackenzie, G. C. (1981). The politics of presidential appointments. New York: Free Press.

Maller, R., \& Zhou, X. (1996). Survival analysis with long-term survivors. New York: John Wiley.

McCarty, N., \& Razaghian, R. (1999). Advice and consent: Senate responses to executive branch nominations, 1885-1996. American Journal of Political Science, 43, 1122-1143.

McCubbins, M. D., \& Schwartz, T. (1984). Congressional oversight overlooked: Police patrols versus fire alarms. American Journal of Political Science, 28(1), 165-179.

Moe, T. M. (1982). Regulatory performance and presidential administration. American Journal of Political Science, 26, 197-224.

Nixon, D. C. (2001). Appointment delay for vacancies on the federal communications commission. Public Administration Review, 61, 483-492.

Nixon, D. C., \& Goss, D. L. (2001). Confirmation delay for vacancies on the circuit courts of appeals. American Politics Research, 29, 246-274.

Nokken, T. P., \& Sala, B. R. (2000). Confirmation dynamics: A model of presidential appointments to independent agencies. Journal of Theoretical Politics, 12(1), 91-112.

Posner, R. (1974). Theories of economic regulation. Bell Journal of Economics and Management Science, 5, 335-358.

Quirk, P. J. (1980). Food and drug administration. In J. Q. Wilson (Ed.), The politics of regulation (pp. 191-235). New York: Basic Books.

Ragsdale, L. (1998). Vital statistics on the presidency. Washington, DC: CQ Press.

Rose, N. L. (1990). Profitability and product quality: Economic determinants of airline safety performance. Journal of Political Economy, 98, 944-964.

Ruckman, P. S., Jr. (1993). The Supreme Court, critical nominations, and the Senate confirmation process. Journal of Politics, 55, 793-805.

Spriggs, J., \& Wahlbeck, P. (1995). Calling it quits: Strategic retirement on the federal courts of appeals, 1893-1991. Political Research Quarterly, 48, 573-597.

Wood, B. D., \& Waterman, R. W. (1991). The dynamics of political control of the bureaucracy. American Political Science Review, 85, 801-828.

Yamaguchi, K. (1991). Event history analysis. Newbury Park, CA: Sage.

David C. Nixon is an associate professor of political science at Georgia State University. He specializes in American political institutions. His work has appeared in Public Administration Review, Journal of Public Administration Research \& Theory, Political Research Quarterly, American Politics Research, and Journal of Law, Economics, \& Organization.

Roisin M. Bentley is a Ph.D. candidate in political science at Georgia State University. She is currently working on her dissertation regarding constituency influence on congressional roll call votes. 